\title{
Effects of 8-week Intensity-Controlled Whole-body Vibration Exercise on Architectural Properties of the Ankle Plantar flexors in Elderly Women: A Randomized Controlled Trial
}

\author{
Dong-Sung Choi', Hae-Dong Lee ${ }^{1^{*}}$ \\ 'Department of Physical Education, College of Sciences in Education, Yonsei University, Seoul, Republic of Korea
}

\begin{abstract}
Received: September 27, 2019

Accepted: October 24, 2019

Published online: October 31, 2019

Keywords:

Elderly

Muscle Architecture

Vibration Intensity

Whole-body Vibration
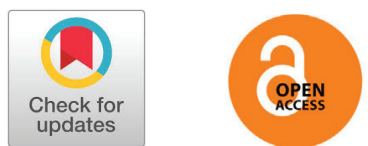

OBJECTIVES This study was to investigate the efficacy of intensity-controlled whole-body vibration exercise on architecture properties of the ankle plantar flexors in elderly women.

METHODS A randomized-controlled design was used. Three groups were recruited in this study (VI group ( $n=15,69.5 \pm 3.9$ years), ET Group ( $n=13,68.5 \pm 4.0$ years), CON Group $(n=15,69.9 \pm 3.3$ years)). Ultrasound was used to measure the architecture parameters (pennation angle, fascicle length and muscle thickness) in the triceps surae muscles. And also, circumference of the lower leg was measured. During the 8-week exercise protocol, elderly women performed exercise program using their body weight on a whole-body vibration device (Pro6 power plate, Power plate International Ltd, UK). Changes in the muscle architecture and circumference were compared between groups by two-way repeated measures of ANOVA ( 2 groups $x$ 4-time points, 3 groups $\times 2$-time points), and an LSD post-hoc test and t-test were performed to determine significant differences between pairwise comparisons. The significance level was set at $\alpha=.05$.

RESULTS Medial gastrocnemius became thicker after the 8 week training session $(p<0.05)$. But there was no statistically significant difference in other parameters between VI and ET group.

CONCLUSIONS The 8-week whole-body exercise resulted in hypertrophy to the ankle plantar flexors, regardless of the vibration intensity control method. It seems that the whole-body vibration exercise could be feasible and doable exercise for elderly women. However, there is little influence on muscle architecture and circumference of ankle plantar flexors.
\end{abstract}

\section{서론}

전신진동운동은 하지 근력, 파워, 균형능력, 신경활 성화 및 구조적 향상을 증가시킬 수 있는 운동방법으로 소개되고 있으며, 그 대상자로는 엘리트 선수들 [1,2]과 건강한 성인 [3,4], 노인 [5-7] 및 뇌졸중 환자들 [8,9]에

*Correspondence: Hae-Dong Lee, Department of Physical Education, Yonsei University, 50 Yonsei-ro Seodaemun-go, Seoul, Republic of Korea; Tel: +82-2-21236188; Fax (Optional): +82-2-2123-8375; E-mail: xbridge1997@yonsei.ac.kr
( T) The Asian Society of Kinesiology and the Korean Academy of Kinesiology 
여성을 대상으로 높은 빈도의 진동운동을 실시한 결과 무를 최대 등척성 및 등속성 신근력이 $15.1 \sim 16.5 \%$ 증 가 하였다고 설명하고 있다[15]. 또한 노인여성들을 대 상으로 10 주간의 전신진동운동 프로그램 후 내측광근 은 $8.7 \%$, 대퇴이두근은 $15.5 \%$ 의 근 비대 현상이 나타 났고 [16], 노인 남성을 대상으로 전신진동운동을 실시 한 결과 근 질량(muscle mass)이 $3.4 \%$ 로 통계적으로 유의하게 증가한 것을 보고하였다[17]. 한편 진동운동 의 부정적인 결과를 설명하면서 진동운동이 저항성 운 동이나 다른 운동들에 비해 근 기능 향상에 긍정적인 영 향을 끼치지 못한다는 사례들도 있다. 노인을 대상으로 6 주간의 진동근력운동을 실시한 그룹과 정적인 운동 을 실시한 그룹의 비교에서 등속성 신근력이 비슷하게 나타났다고 하였으며[18], 성인 여성을 대상으로 5주 간의 전신진동운동을 실시한 결과 무릎 신근력과 점프 수행능력의 비슷한 결과가 나타났다고 하였다[1]. 또 한 뇌졸중 환자들에게 전신진동운동을 실시한 결과 전 신진동운동이 근육의 구조에는 큰 영향을 미치지 못하 였다고 하였으며 [9], 6 주간의 전신진동운동을 건강한 성인을 대상으로 수행하여 발목의 주요 근육들의 근 활 성화를 살펴본 결과 운동 전과 후에 비슷한 결과를 나 타냈다고 하였다[19].

이와 같이 선행연구에서는 진동운동의 긍정적인 효 과가 주를 이루고 있지만, 진동운동이 긍정적인 효과를 나타내지 못했다는 연구들도 제시되고 있는 상황이다 $[1,9,18,19]$. 결국 진동운동의 효과에 대해 일치된 의 견들을 도출하지 못하고 있는 실정이다.

진동운동 장비의 밑판을 통해 발생되어 전달되는 진 동 빈도(frequency)와 폭(amplitude) 및 진동의 세기 (magnitude)는 진동 강도에 큰 영향을 미치는 요소인 데[20], 이러한 진동강도의 점진적인 증가는 노인의 하 지 근 기능 [7,21]과 체력향상[18]에 긍정적인 영향을 미친다고 하였다. 특히, 진동강도(intensity)와 진동시 간(duration)의 점진적인 증가로 인하여 노인의 하지 근 기능 향상에 긍정적인 영향을 미쳤다고 보고한 선행연 구들도 있은데, 10 주간 진동강도와 진동시간의 점진적 인 증가가 노인 여성의 최대 등척성 수축 값을 증가시켰 으며, 내측광근과 대퇴이두근에 근비대(hypertrophy) 현상이 나타났다고 하였다[16]. 또한 노인들을 대상으 로 진동 폭과 진동 노출 시간의 점진적인 증가를 통해 족저굴곡근력이 크게 증가한 것을 보고하였으며[7], 노
인을 대상으로 수행한 연구는 아니지만 12 주간 젊은 여 성을 대상으로 진동강도와 진동노출시간의 점진적인 증 가를 통해 정적, 동적 무릎 신전근력이 증가한 것을 보 고하고 있다[12].

선행연구들의 결과를 통해서 점진적인 진동강도의 증가와 더불어 점진적인 진동노출시간의 증가 또한 하 지의 근 기능과 근육의 구조, 체력 및 신체 기능에 긍정 적인 영향을 미치는 것으로 생각된다. 그러나 진동강도 와 진동시간의 효과를 체계적으로 비교하여 하지의 근 구조에 긍정적인 영향을 끼치는 요소를 검증한 연구들 은 부족한 실정이다. 따라서 진동강도와 진동노출시간 중 노인의 하지 근 구조에 효과적이고 긍정적인 영향을 주는 요소를 검증 할 수 있다면 노인들이 전신진동운동 을 활용할 때 보다 효율적인 운동 프로그램 방안을 제 공 해 줄 수 있을 것으로 판단된다.

본 연구에서는 진동강도의 점진적인 증가와 진동시 간의 점진적인 증가 중 어떠한 요소가 노인 여성의 족저 굴곡근의 내·외적 두께, 근섬유다발길이 및 우상각에 긍 정적인 영향을 미치는지를 살펴보고자 한다.

\section{연구방법}

\section{연구대상}

65 세 이상의 노인 100 명을 대상으로 S시 소재 S병 원에서 제작한 문진표와 $\mathrm{PAR}-\mathrm{Q}$ 검사도 함께 시행하여 운동수행 가능여부를 구분하였다. 현재나 과거에 근골 격, 신경, 심혈관계 질환 및 골다공증이 없는 사람과 제 자리 앉았다 일어서기가 가능한 대상자를 1 차 대상자 로 선발하였다. 1차로 선발된 대상자들에 한하여 서울 시에 소재하는 S 병원에서 하지 주요 관절(Hip, Knee, Ankle Joint)의 X-Ray 촬영 한 후 이상 없는 사람을 최 종 대상자로 선정하였다.

본 연구의 대상자는 기초의학검사를 통하여 전신진 동운동 수행이 가능하고, 근 구조 측정이 가능한 65 세 이 상 노인 여성 43명이다(VI 점증 그룹: 15 명, $\mathrm{ET}$ 점증 그 룹: 13명, Con 그룹: 15명). Vibration Intensity (VI) 점 증 그룹은 8 주간 전신진동 수행 중 진동강도(진동 빈도 와 진폭)는 점진적으로 증가시키고 진동노출시간은 고정 시키는 그룹이다. Vibration Exporse Time (ET) 점증 그룹은 진동노출시간을 점진적으로 증가시키면서 진동 강도는 일정하게 유지시키는 그룹이다. Control (Con) 
그룹은 전신진동운동을 전혀 수행하지 않는 그룹이다. 모든 대상자들은 무작위 추출방법을 활용해 세 그룹에 무작위로 배정하였으며, 각 그룹에 속한 대상자들은 본 인이 속한 그룹을 알지 못하도록 블라인딩 하였다.

운동 시작 전 세 그룹에 배정 된 대상자들의 신체적 특성은 비슷한 결과가 나타났다<Table $1>$.

\begin{tabular}{|c|c|c|c|c|}
\hline \multirow{2}{*}{ Parameter } & \multicolumn{2}{|c|}{$\begin{array}{c}\text { WBV } \\
(\mathrm{N}=28)\end{array}$} & \multirow{2}{*}{$\begin{array}{c}\mathrm{CON} \\
(\mathrm{N}=15)\end{array}$} & \multirow[t]{2}{*}{$p$-Value } \\
\hline & VI $(\mathrm{N}=15)$ & $\mathrm{ET}(\mathrm{N}=13)$ & & \\
\hline Age (years) & $69.5 \pm 3.9$ & $68.5 \pm 4.0$ & $69.9 \pm 3.3$ & 0.492 \\
\hline Weight (kg) & $59.8 \pm 7.2$ & $60.3 \pm 7.7$ & $60.3 \pm 7.0$ & 0.974 \\
\hline Height $(\mathrm{cm})$ & $155.3 \pm 5.2$ & $155.0 \pm 4.6$ & $153.7 \pm 4.0$ & 0.645 \\
\hline \multicolumn{5}{|c|}{$\begin{array}{l}\text { ※ WBV: Whole Body Vibration Group. } \\
\text { ※ VI: Vibration Intensity Increase Group, ET: Exposure Time Increase } \\
\text { Group, CON: Control Group. }\end{array}$} \\
\hline
\end{tabular}

본 연구를 진행하기 전 연구 대상자의 윤리적 보호 와 안전을 위해 실험 방법과 절차는 대학교 기관 내 IRB (YUIRB-2012-013-02) 승인을 받았으며, 모든 대상자 에게 운동 프로그램과 실험을 수행 하기 전 실험의 목 적과 방법 및 절차에 대하여 충분히 설명하고, 실험 참 여에 동의하는 대상자에게만 실험참가 동의서 받았다.

모든 대상자들은 진동운동 프로그램 참여하고 있는 동안 신체활동 수준을 파악하기 위해 운동 중단 4 주 후 측정이 완료되고 나서 $\mathrm{I}-\mathrm{PAQ}$ 검사를 실시하였다.

\section{실험설계}

65 세 이상 여성을 대상으로 문진표를 작성하고, $\mathrm{PAR}-\mathrm{Q}$ 검사를 실시하였다. 문진표와 $\mathrm{PAR}-\mathrm{Q}$ 검사를 통과한 대상자들은 실험 참가 전 기초 의학 검사를 실 시하였다.

최종적으로 선발된 대상자들은 VI 점증 그룹, $\mathrm{ET}$ 점 증 그룹, Con 그룹으로 무작위 추출방식으로 배정하였 다. 진동운동은 8 주간, 주 3 회, 하루에 $11 \sim 32$ 분 정도 범위의 진동운동 프로그램을 수행하였다. 진동운동 시 작 전 0 주, 운동시간 경과 4 주, 8 주 및 운동 프로그램 중단 후 4 주 뒤에 각각 족저굴곡근의 내적구조와 하퇴 의 외적 둘레 변화도 살펴보았다.

\section{운동 프로그램}

노인 여성을 대상으로 진동운동을 수행하여 하지근
력이 많이 증가된 선행연구[16]의 진동강도와 진동시 간을 참고로 하였으며, 족저굴곡력을 최대화 시킬 수 있는 운동 자세를 파악하여 진동운동 프로그램을 구성 하였다. 진동운동 시 Power Plate사의 Pro 6 (Power Plate International Ltd., London, UK) 장비를 사용하 였다. 본 연구에 사용된 진동운동기의 진동빈도 범위는 25 40 Hz이며, 진폭은 $1.1 \sim 2.5 \mathrm{~mm}$ 범위를 지닌다. 진동운동 전 준비운동과 정리운동을 각 5 분씩 실시하 였다. 진동운동은 통제그룹을 제외한 모든 대상자들에 게 8주 간, 주 3 회씩, 일일 약 40 분씩 실시하였다. 각 그 룹 별 진동운동의 강도와 운동기간 설정은 〈Table 2> 과 같다. 진동운동은 Tow leg calf raise (TLCR), Half squat and heel down (HSHD), Half squat and calf raise (HSCR), One leg calf raise (OLCR) 등 4개의 운 동 자세로 구성하였다[16].

\section{측정 및 분석 방법}

\section{인체 및 하퇴의 둘레 측정}

준비운동을 마친 대상자들은 침대에 엎드리도록 하 였다. 발목관절의 비골 외측(Lateral malleolus)과 에서 시작하여 무릎 관절 위치의 비골두(Head of fibula)까지 의 길이를 측정하였으며, 그 길이에 대한 근위 $30 \%$ 되 는 지점의 둘레를 측정하였다.

\section{초음파 영상 측정 및 분석}

근섬유 다발의 배열각인 우상각, 길이 및 근 두께 를 촬영하기 위해 초음파영상장비(LOGICSCAN 128 EXT-1, Lithuania)가 사용되었다. sampling frequency 는 $40 \mathrm{~Hz}$ 로 하여 모든 측정에 동일하게 적용하였다. 준 비운동을 한 대상자는 침대에 엎드려 누운 상태로 무릎 관절을 중심으로 다리를 완전히 신전 시킨 상태에서 발 목관절의 비골 외측(Lateral malleolus)과에서 무릎 관 절 위치의 비골두(Head of fibula)까지의 길이를 측정 하였으며, 그 길이에 대한 근위 $30 \%$ 지점의 둘레를 측 정하였다. 먼저 외측 비복근의 횡단면(CSA)을 측정하여 근육의 위치와 배열들을 검사 한 후 장축(Longitudinal) 방향으로 외측비복근을 측정하고, 동일한 순서를 적용 하여 내측비복근도 측정하였다. 촬영된 영상은 영상파 일로 저장하였다. 실시간 초음파 장치와 프로브를 이용 하여 $40 \mathrm{~Hz}$ 로 초음파 영상을 수집하였다. 
Table 2. Exercises program protocol

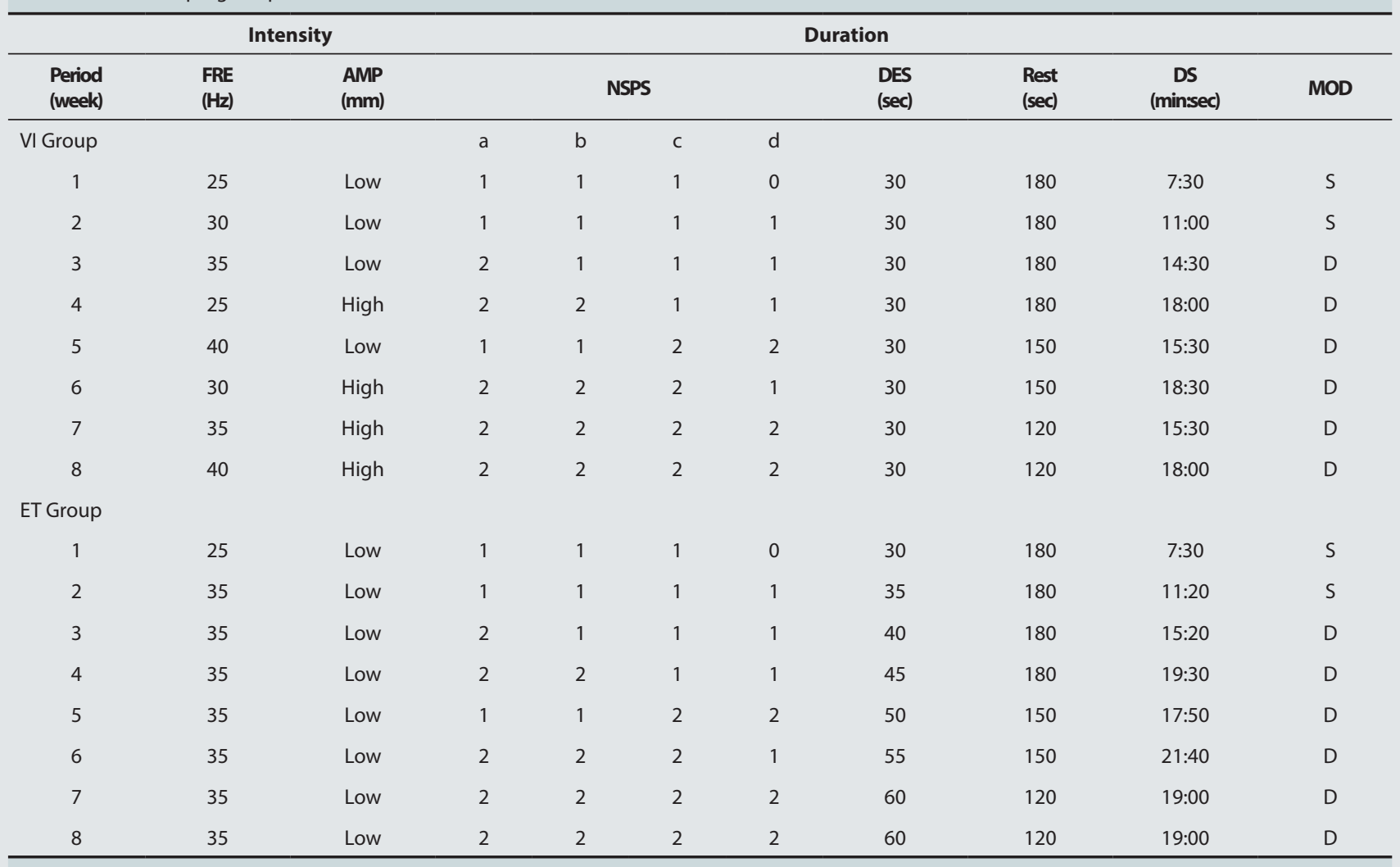

※ VI Group: Vibration Intensity increasing, ET Group: Exposure Time increasing Group.

※ a: Two leg calf raise (TLCR), b: Half squat and heel down (HSHD), c: Half squat and calf raise (HSCR), d: One leg calf raise (OLCR).

※ High amplitude (2.5 $\mathrm{mm}$ [peak to peak ; Low amplitude (1.1 $\mathrm{mm}$ [peak to peak]).

※ Modalities (S: Statics; D: Dynamics)

※ FRE: Frequency, AMP: Amplitude, NSPS: Number of series per exercise, DES: Duration of each session(s), DS: Duration of session(min; sec), MOD:

Modalities.

수집된 초음파 영상은 VirtualDub(http://www. virtualdub.org) 동영상 편집 프로그램을 사용하여 영상 파일의 압축을 해제 시킨 후, 압축 푼 영상을 ImageJ(http://rsbweb.nih.gov/ij/download.html)를 영상 측정 프로그램을 사용하여 내측과 외측 비복근 의 우상각(Pennation angle: PA), 근섬유다발의 길이 (Fascicle length: FL) 및 근 두께(Muscle thickness: $\mathrm{MT}$ )를 측정 하였다<Figure $1>$.

\section{통계처리}

본 연구의 목표 피험자 수를 산정하기 위해 G-power 프로그램을 활용하였다. 목표 피험자의 수는 기존의 유사한 연구[24]를 기준으로 하였고, effect size는 0.5388159 이며, $a($ 유의수준)은 0.05로, 검정력 $(1-\beta)$

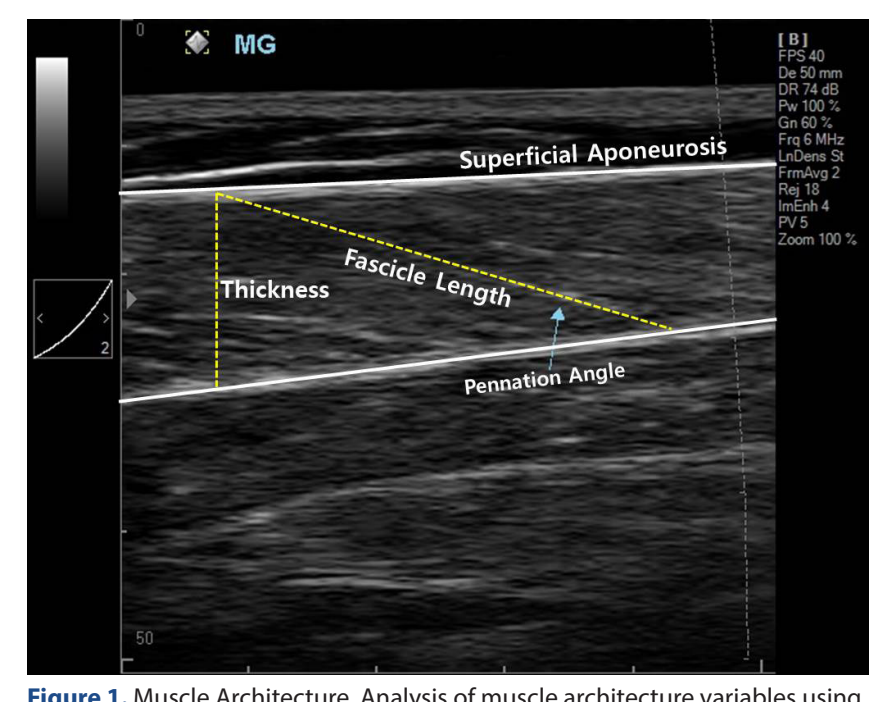

Figure 1. Muscle Architecture. Analysis of muscle architecture variables using a ultrasounds imaging technique 
정 기간에 대한 족저굴곡근의 내적구조와 외적 둘레 값 을 비교하기 위한 Repeated Measurement of ANOVA test를 사용하기 위한 최소 피험자는 총 40 명으로 계산 되며, 본 연구에서는 drop-out rate는 고려하여 43명 으로 선정하였다.

그룹에 속한 각 대상들의 운동 전 신체적 특성을 비 교 해 보기 위해 One-way ANOVA를 적용하였다.

전신진동운동이 노인 여성의 족저굴곡근의 내적 구 조와 둘레에 어떠한 영향을 미치는지 검증하기 위해 2 개의 그룹(VI 점증 그룹, $\mathrm{ET}$ 점증 Group)과 4회의 운동 기간(0주, 4 주, 8 주, 운동 중단 4주 후)에 대한 이원변량 반복측정 분산분석(Two-way ANOVA with repeated measures)을 사용하였다. 상호작용 효과에 대한 사후 검증으로는 어떤 그룹에서 측정 시기별로 차이가 있는 지 구체적으로 알아보기 위해 일원 반복측정 분산분석 (One-way Repeated measure of ANOVA)을 사용하 였으며, 이때의 사후검증으로 $\mathrm{LSD}$ 를 적용하였다. 두 그룹 간 차이에 대해서는 각 측정시기에서 t-test를 사 용하였다.

또한 3개의 그룹(VI 점증그룹, $\mathrm{ET}$ 점증 Group, $\mathrm{CON}$ Group)과 2회(0주, 8주)의 운동기간에 대해 반복측정 분산분석 (Repeated Measures ANOVA)을 사용하였 으며, 상호작용 효과에 대한 사후검증으로는 어떤 집단
에서 측정 시기별로 차이가 있는지 구체적으로 알아보 기 위해 t-test가 사용되었고, 세 그룹 간 차이에 대해 서는 각 측정시기에서 One-way ANOVA를 적용한 후 사후검증으로 $\mathrm{LSD}$ 가 사용되었다.

각각의 그룹에서 측정 시기별로 어떤 차이점이 나타 나는지 알아보기 위해 One-way Repeated measure of ANOVA를 적용하였으며, 사후검증으로 $\mathrm{LSD}$ 를 사 용하였다.

본 연구에서는 Kolmogorov-Smirrnov 방법 으로 정규성 분포를 확인하였으며, 구형성 가정은 Greenhouse-Geisser 방법을 사용하였다.

모든 분석은 SPSS 18.0 통계프로그램을 활용하였으 며, 모든 변인들에 대해 평균과 표준편차를 산출하였고, 통계적 유의 수준은 $\mathrm{p}<.05$ 로 설정하였다.

\section{결과}

\section{근육의 내적 구조 변화}

\section{내측비복근}

진동운동 세 그룹 간의 비교에서 내측비복근의 근 두께는 그룹(VI 점증 그룹, $\mathrm{ET}$ 점증 그룹, Control 그 룹)과 측정시기( 0,8 주)에서 상호작용 효과가 나타나지

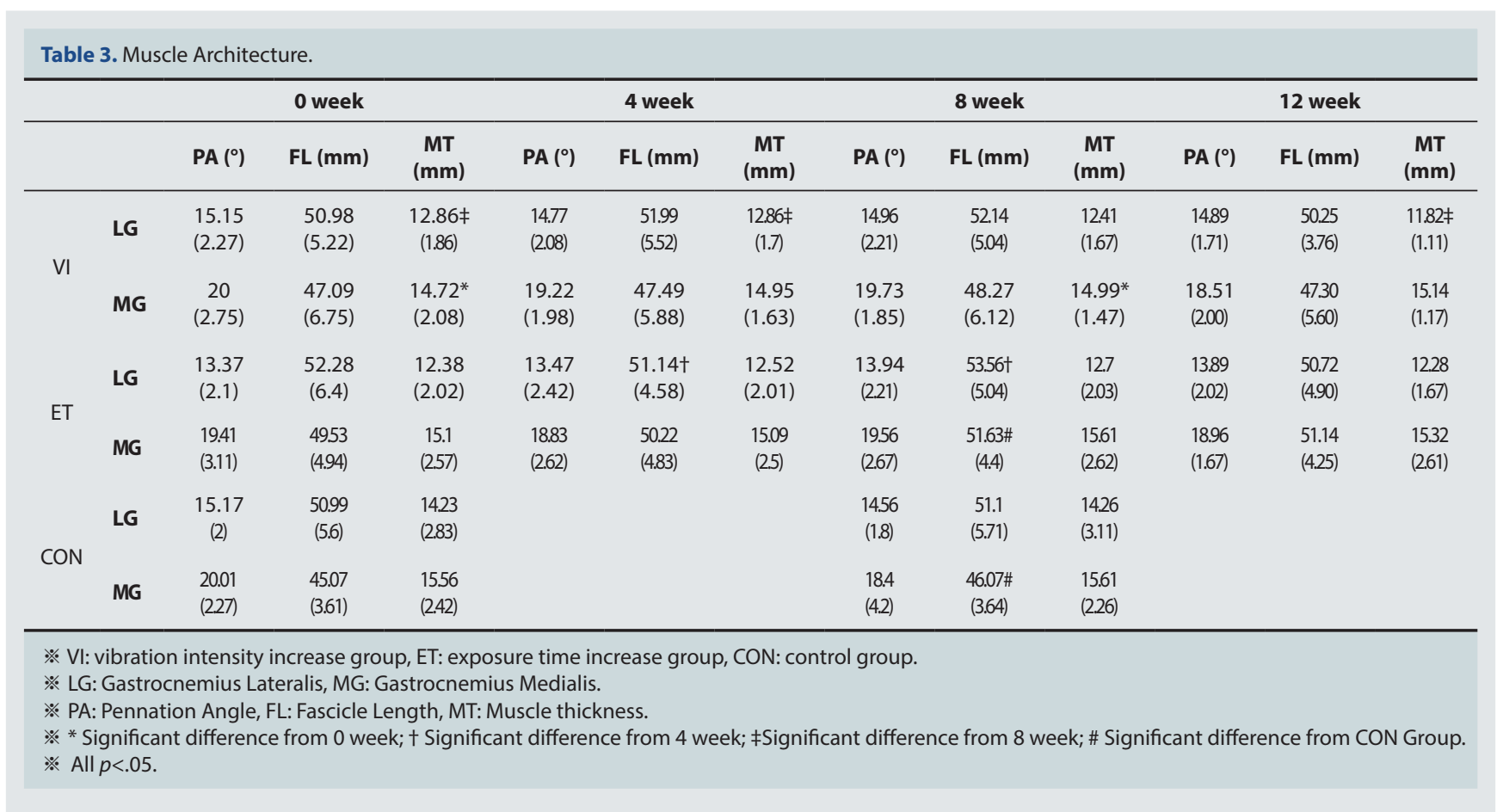


않았으며 $(\mathrm{F}=1.364, p=0.267)$, 그룹 $(\mathrm{F}=0.456, p=$ 0.637)의 주효과 비교에서 통계적인 유의차가 나타나지 않았다. 그러나 측정시기 $(\mathrm{F}=6.123, p=0.018)$ 의 주 효과 비교에서는 통계적인 유의차가 나타났다. 사후 검 증 결과, $\mathrm{VI}$ 점증 그룹은 0 주 보다 8주 $(p<0.05)$ 와 12 주 $(p<0.05)$ 가 내측비복근의 근 두께가 통계적으로 유 의하게 증가하였다. 그러나 ET 점증 그룹과 Control 그 룹에서는 통계적으로 유의한 차이가 나타나지 않았다 $(p$ $>0.05$ ) <Table 3>.

각 시기별 그룹 간의 변화를 살펴 본 결과, $\mathrm{ET}$ 점증 그룹은 Control 그룹 보다 8주에서 내측비복근의 근섬 유 다발의 길이가 통계적으로 유의하게 더 긴 것으로 나 타났다 $(p<0.05)<$ Table $3>$.

\section{외측비복근}

진동운동 두 그룹 간의 비교 중 각 그룹별로 측정시 기 간의 변화를 살펴본 결과, VI 점증 그룹에서는 통계적 인 유의 차가 나타나지 않았고 $(\mathrm{F}=2.612, p=0.064)$, $\mathrm{ET}$ 점증 그룹에서는 통계적인 유의 차가 나타났다 $(\mathrm{F}=$ $3.406, p=0.028)$. 사후검증 결과, $\mathrm{ET}$ 점증 그룹은 4 주 보다 8주가 통계적으로 유의하게 근섬유다발의 길이 가 긴 것으로 나타났다 $(p<0.05)$. 그러나 VI 점증 그룹 에서는 통계적인 유의차가 나타나지 않았다 $(p>0.05)$.

\section{하퇴 둘레의 변화}

진동운동 세 그룹간의 비교에서 하퇴의 둘레는 그룹 (VI 점증그룹, $\mathrm{ET}$ 점증그룹, Control 그룹)과 측정시기 $(0,8$ 주 $)$ 에서 상호작용 효과가 나타나지 않았으며 $(\mathrm{F}=$ $2.103, p=0.135)$, 그룹 간 $(\mathrm{F}=0.252, p=0.779)$ 주 효과 비교에서도 통계적인 유의차가 나타나지 않았다. 그러나 측정시기 $(\mathrm{F}=14.496, p=0.002)$ 의 주효과 비 교에서는 통계적인 유의차가 나타났다. 각 그룹별로 측 정시기 간의 변화를 살펴본 결과, $\mathrm{ET}$ 점증 그룹은 0 주 보다 8주의 하퇴 둘레가 통계적 유의하게 크게 나타났 고 $(p<0.05)$, Control 그룹도 0주보다 8주의 하퇴 둘 레가 통계적으로 유의하게 크게 나타났다 $(p<0.05)$.

\section{논의}

본 연구에서는 근력에 영향을 미치는 근육의 내적 구조의 변화 양상을 초음파 영상 장비를 활용하여 살 펴보았다. 족저굴곡근을 대표해서 내측비복근과 외측
비복근의 우상각과 근섬유다발의 길이 및 근 두께를 측 정하였으며, 진동운동 프로그램 전 후 근육의 내적구조 에 미치는 영향을 살펴보았다 또한 외적구조의 변화를 살펴보기 위해 족저굴곡근의 둘레 변화도 살펴보았다.

근육 내 수축 요소인 근섬유는 근육의 운동방향과 평 행 또는 비스듬히 배열되어 있다. 이러한 근육의 공간적 구조 배열은 근육의 생리학적 단면적에 영향을 미치게 되고, 근력을 결정 짖는 아주 중요한 요소로 작용 될 뿐 아니라, 근육의 운동 범위와 수축 속도 등에도 영향을 미 치는 중요한 요인으로 작용한다[22,23]. 또한 근 두께의 증가도 근 기능과 근력에 긍정적인 영향을 미치게 된다.

선행연구[16]에서는 노인여성들을 대상으로 10 주간 의 전신진동운동 프로그램의 수행이 근 비대 현상에 영 향을 미친 것을 보고 하였고, 노인 남성을 대상으로 전 신진동운동을 실시하여 근 질량(muscle mass)의 변화 를 살펴본 결과 운동 프로그램 후 근 질량이 통계적으로 유의하게 증가한 것을 보고하였다[17]. 이처럼 진동운 동은 근육의 구조에 긍정적인 영향을 미친다고 보고한 선행연구들이 있지만 진동운동이 근육의 구조적 특성에 긍정적인 영향을 미치지 못한다는 선행연구도 제시되고 있다. 뇌졸중 환자들에 게 전신진동운동을 실시하여 근 육의 구조와 근력 및 균형 능력을 평가한 결과 근육의 구조에는 큰 변화가 나타나지 않았다고 하였고[9], 또 다른 선행연구[24]에서는 노인을 대상으로 8주간의 전 신진동운동을 수행하여 발바닥쪽굽힘근의 내적 구조를 살펴본 결과 전신진동운동은 노인여성의 하지 근 구조 에 크게 영향을 미치지 못했다고 결론을 제시하고 있다.

본 연구에서는 진동운동을 수행한 두 그룹 간의 비교 에서도 진동운동이 내측비복근의 우상각과 근섬유다발 의 길이에는 통계적으로 유의한 변화들이 관찰되지 않 았다. 즉, 전신진동운동 프로그램이 내측비복근의 우상 각과 근섬유 다발의 길이에는 영향을 미치지 못 한 것 을 알 수 있다.

각 그룹별 측정 시기의 변화를 살펴본 결과 VI 점증 그룹은 0주 보다 8주의 근 두께가 더 큰 것으로 나타났 는데, 이는 전신진동운동 시 진동강도의 점진적인 증가 는 내측비복근의 근 두께에 긍정적인 영향을 미치는 것 으로 판단된다. 이러한 결과는 노인여성들을 대상으로 10 주간의 전신진동운동 프로그램 후 내측광근과 대퇴 이두근에 근 비대 현상이 나타났다는 선행연구 [16]와 노인 남성을 대상으로 전신진동운동을 실시 한 후 근 질 
량이 통계적으로 유의하게 증가한 것을 보고 한 선행연 구[17]의 결과를 지지 해 주고 있다. 그러나 근 두께의 변화 값은 매우 미비한 증가를 보여주고 있으며, VI 점 증 그룹의 내측비복근외에 다른 요인에서는 긍정적인 변 화가 나타나지 않았으므로, 8주간의 진동운동은 족저굴 곡근의 근 비대에 큰 영향을 주지 못한 것으로 판단 할 수 있다. 그러나 선행연구[16]에 의거하여 진동운동을 8 주 보다 10 주나 12 주 이상 수행하게 되면 하지 근육의 근 비대가 두드러지게 관찰 될 수 있을 것으로 생각된다.

본 연구에서는 근육의 내적구조의 변화와 더불어 근육의 외적인 변화 여부를 살펴보았는데, 각 그룹별 로 측정시기 간의 변화를 살펴본 결과 $\mathrm{ET}$ 점증 그룹과 Control 그룹은 0주 보다 8주가 더 높은 근 두께를 나타 냈다. 그러나 근 두께의 변화양은 매우 미비한 결과여서 진동운동 수행이 근육의 외적인 변화에 큰 영향을 주지 못한 것으로 판단된다. 이러한 결과는 8 주간의 진동운 동이 근육의 구조에는 영향을 미치지 않았다고 보고한 선행연구 $[9,24]$ 의 결과와 일치하고 있다.

본 연구의 제한점은 효율적인 진동운동 강도를 검증 하고자 노인여성만을 대상자로 삼았기 때문에 노인남 성과 일반 성인에게 일반화 할 수 없는 점이다. 또한 본 연구의 트레이닝 기간은 8주로 제한 되었지만 트레이 닝 기간의 연장에 따라 진동운동의 효과가 보다 증가할 가능성이 있기 때문에 향후 보다 장기적인 중재 연구가 필요하다. 이 밖에도 진동운동의 효과를 검증하기 위해 8 주간 진동운동기 위에서 진동은 없이 진동운동그룹과 같은 동작을 수행하는 그룹을 편성하지 못한 것이 본 연 구의 제한점이다.

\section{결론}

본 연구에서 노인여성을 대상으로 전신진동운동의 효과를 재검증하고, 효율적인 진동강도를 발견하여 보 다 긍정적인 영향을 미치는 진동운동 프로그램을 제공 하고자 하였다. 이를 위해 8 주간의 전신진동운동 시 진 동강도(진동 빈도와 진폭)를 점진적으로 증가시킨 그 룹(VI)과 진동노출시간을 야점진적으로 증가시킨 그룹 (VE) 및 운동을 시키지 않는 그룹(Con)을 구성하였으 며, 하지 족저굴곡근의 내적구조와 외적 둘레 변화에 어 떠한 영향을 미치는지 살펴보았다. 본 연구 결과 노인 여성을 대상으로 8 주간의 진동운동을 실시한 VI 점증그
룹에서는 내측비복근의 근두께가 증가한 것으로 나타났 으나, ET 점증 그룹과 Con 그룹에서는 큰 차이가 발생 되지 않았다. 그리고 $\mathrm{VI}$ 점증 그룹과 $\mathrm{ET}$ 점증 그룹 비 교에서는 족저굴곡근의 내·외적 두께, 근섬유다발 길이 및 우상각의 차이를 발견하지 못했다.

\section{Conflicts of Interest}

The authors declare no conflict of interest.

\section{References}

1. Delecluse C, Roelants M, Diels R, Koninckx E, Verschueren S. Effects of whole body vibration training on muscle strength and sprint performance in sprint-trained athletes. Int J Sports Med. 2005; 26(8):662-668.

2. Rønnestad BR, Ellefsen S. The effects of adding different whole-body vibration frequencies to preconditioning exercise on subsequent sprint performance. J Strength Cond Res. 2011; 25(12):3306-3310.

3. Roelants M, Verschueren SM, Delecluse C, Levin O, Stijnen V. Whole-body-vibration-induced increase in leg muscle activity during different squat exercises. J Strength Cond Res. 2006; 20(1):124-129.

4. Marin PJ, Santos-Lozano A, Santin-Medeiros F, Delecluse C, Garatachea N. A comparison of training intensity between whole-body vibration and conventional squat exercise. J Electromyogr Kinesiol. 2011; 21(4):616-621.

5. Bogaerts AC, Delecluse C, Claessens AL, Troosters T, Boonen S, Verschueren SM. Effects of whole body vibration training on cardiorespiratory fitness and muscle strength in older individuals. Age Ageing. 2009; 38(4):448-454.

6. Marin PJ, Santos-Lozano A, Santin-Medeiros F, VicenteRodriguez G, Casajus JA, Hazell TJ. Whole-body vibration increases upper and lower body muscle activity in older adults: Potential use of vibration accessories. J Electromyogr Kinesiol. 2011; 22(3):456462.

7. Rees SS, Murphy AJ, Watsford ML. Effects of whole-body vibration exercise on lower-extremity muscle strength and power in an older population. Phys Ther. 2008; 
88(4):462-470.

8. Choi DS. Effects of Vibration Stimulation Intensity during Whole-body Vibration Exercise on Soleus H-reflex in Hemiplegic Stroke Patients. The Official Journal of the Korean Association of Certified Exercise Professionals. $2014 ; 16(4): 83-92$.

9. Marin PJ, Ferrero CM, Menendez H, Martin J, Herrero AJ. Effects of Whole-Body Vibration on Muscle Architecture, Muscle Strength, and Balance in Stroke Patients: A Randomized Controlled Trial. Am J Phys Med Rehabil. 2013; 92(10):881-888.

10. Bosco C, Colli R, Introini E, Cardinale M, Tsarpela O, Madella A. Adaptive responses of human skeletal muscle to vibration exposure. Clin Physiol. 1999; 19(2):183-187.

11. Cochrane DJ, Stannard SR. Acute whole body vibration training increases vertical jump and flexibility performance in elite female field hockey players. Br J Sports Med. 2005; 39(11):860-865.

12. Delecluse C, Roelants M, Verschueren S. Strength increase after whole-body vibration compared with resistance training. Med Sci Sports Exerc. 2003; 35(6):1033-1041.

13. Roelants M, Delecluse C, Verschueren SM. Whole-bodyvibration training increases knee-extension strength and speed of movement in older women. J Am Geriatr Soc. 2004; 52(6):901-908.

14. Russo CR, Lauretani F, Bandinelli S. et al. Highfrequency vibration training increases muscle power in postmenopausal women. Arch Phys Med Rehabil. 2003; 84(12):1854-1857.

15. Verschueren SM, Roelants M, Delecluse C, Swinnen S, Vanderschueren D, Boonen S. Effect of 6-month whole body vibration training on hip density, muscle strength, and postural control in postmenopausal women: A randomized controlled pilot study. J Bone Miner Res. 2004; 19(3):352-359.

16. Machado A, García-López D, González-Gallego J, Garatachea N. Whole-body vibration training increases muscle strength and mass in older women: a randomized-controlled trial. Scand J Med Sci Sports. 2010; 20(2):200-207.

17. Bogaerts A, Delecluse C, Claessens AL, Coudyzer W, Boonen S, Verschueren SM. Impact of whole-body vibration training versus fitness training on muscle strength and muscle mass in older men: a 1-year randomized controlled trial. J Gerontol A Biol Sci Med Sci. 2007; 62(6):630-635.

18. Bautmans I, Van Hees E, Lemper JC, Mets T. The feasibility of Whole Body Vibration in institutionalised elderly persons and its influence on muscle performance, balance and mobility: a randomised controlled trial. BMC Geriatr. 2005; 22:5-17.

19. Martinez F, Rubio JA, Ramos DJ, Esteban P, Mendizabal S, Jimenez F. Effects of 6-week whole body vibration training on the reflex response of the ankle muscles: a randomized controlled trial. Int J Sports Phys Ther. 2013; 8(1):15-24.

20. Nordlund MM, Thorstensson A. Strength training effects of whole-body vibration? Scand J Med Sci Sports. 2007; $17(1): 12-17$.

21. Hazell TJ, Jakobi JM, Kenno KA. The effects of whole-body vibration on upper- and lower-body EMG during static and dynamic contractions. Appl Physiol Nutr Metab. 2007; 32(6):1156-1163.

22. Gans C, Bock WJ. The functional significance of muscle architecture--a theoretical analysis. Ergeb Anat Entwicklungsgesch. 1965; 38:115-142.

23. Herzog W, ter Keurs HE. A method for the determination of the force-length relation of selected in-vivo human skeletal muscles. Pflugers Arch. 1988; 411(6):637-641.

24. Han BR, Lee DY, Jeong SW, Lee HD. Changes in the Biomechanical Properties of Ankle Plantarflexors Following 8-week Resistance Training with or without Whole-Body Vibration in Older Women. Korean Journal of Sport Biomechanics. 2014; 24(4):399-415. 